\title{
КОЛЕБАТЕЛЬНОЕ ВОЗМУЩЕНИЕ ЭРГАТИЧЕСКОЙ СИСТЕМЫ
}

\author{
${ }^{1}$ Мазуркин П.М. \\ ${ }^{1}$ ФГБОУ ВПО «Поволжский государственный технологический университет Минобрнауки \\ России», Йошкар-Ола, Россия (424000, Йошкар-Ола, пл. Ленина, 3), e-таil: kaf_po@таil.ru
}

\begin{abstract}
Дана концепция выявления фундаментальных закономерностей распределения структуры и динамики функционирования систем с учетом поведения живого вещества, на основе вейвлет-анализа асимметричных структурно-функциональных колебательных возмущений, для научно-технической экспертизы ретроспективы научно-технологического и социально-экономического развития и роста. Показана характеристика России как сильно колеблющейся эргатической системы. Даны формы таблиц для проведения полного факторного анализа по предлагаемому методу анализа иерархий. Рассмотрен подробно пример эргатической системы теплоцентрали города Йошкар-Ола как смесь показателей выпуска продукции и параметров загрязнения окружающей среды. Между выработкой электрической и тепловой энергии наблюдается сильная теснота факторной связи, а между видами загрязнения (побочная продукция) слабая и средняя связь, что объясняется больше высокой погрешностью исходных данных по концентрации загрязняющих веществ по сравнению с измерениями количества выпускаемой продукции.

Ключевые слова: эргатическая система, структура, поведение, колебание, закономерности
\end{abstract}

\section{OSCILLATORY PERTURBATIONS ERGATIC SYSTEM}

\section{${ }^{1}$ Mazurkin P.M.}

${ }^{1}$ Federal State Educational Institution of Higher Professional Education "Volga State Technological University, Ministry of Education of Russia", Yoshkar-Ola, Russia (424000, Yoshkar-Ola, Lenin square, 3), e-mail: kaf_po@mail.ru

A concept to understand the fundamental laws of distribution of the structure and dynamics of the functioning of the systems , taking into account the behavior of living matter on the basis of wavelet analysis of asymmetric structure-function of the vibrational disturbances to the scientific and technical expertise retrospective scientific, technological and socio -economic development and growth. Shows the characteristics of Russia as highly fluctuating ergatic system. Given the form of tables for a full factorial analysis of the proposed method of analysis of hierarchies. We consider in detail the example ergatic district heating system of the city of Yoshkar-Ola as a mixture of output and performance parameters of pollution. Between development of electric and thermal energy the strong narrowness of factorial communication is observed, and between the forms of pollution (by-products) the weak and the average bond, due to more high accuracy input data on the concentration of pollutants in comparison with the measurements of the number of products.

Key words: ergatic system, structure, behavior, oscillation, patterns

Введение. В общем смысле под эргатической будем понимать систему с учетом живого вещества (понятия живого и косного вещества по В.И. Вернадскому). В частном случае эргатическая система - это система с включением людей, например, мировая экономическая система, государство, промышленность, сельское хозяйство, город, предприятие и др.

Простейшей эргатической структурой является модель «человек-машина», и в ней безоговорочно первично поведение человека-оператора.

На многих примерах $[1,5,7,11]$ было показано, что всё живое адаптируется к условиям существования волнообразно, с колебательным изменением своего поведения. Иначе говоря, живое вещество «признает» первичность косного вещества. Но люди своим развивающимся 
корпоративным разумом (точнее, накоплением информации, причем информацию мы понимаем как меру взаимодействия) чаще всего отошли от природы.

Хотя многие люди относятся к окружающей их живой природе трепетно и с осознанным пониманием к жизнедеятельности растений и животных, но в целом человечество, хозяйственно покорив биосферу Земли, ведет себя весьма хаотично [3, 5, 7]. Колебательное возмущение давно уже стало биологически не адаптационным, а чисто техническим (косным).

Моделирование устойчивыми законами прогнозов до 2100 года 14 сценариев развития человечества показывает [3], что движение по тренду в виде закона экспоненциального роста или гибели является только простой идеализацией. В программной среде World3 не были учтены особенности колебательной биологической адаптации к изменениям в климате и конкурентной среде людей, стран и их сообществ за природные ресурсы.

Поведение России. Все же многие страны и в целом человечество движутся, хотя и медленно, более или менее осознавая свое прошлое поведение. Но Россия здесь явное исключение [5]: она движется вот уже более 300 лет импульсными колебаниями с сильнейшими возмущениями, когда амплитуда гораздо больше среднестатистического тренда. Именно по этой причине, как нам представляется, Росстат не стал публиковать многолетние статистические данные: все равно ученые не умеют их моделировать волновыми колебательными возмущениями. А, например, в Финляндии открыто находятся в Интернет ежегодные статистические данные с 1913 года, то есть с момента образования государственности.

Ручное управление страной больше происходит по вновь возникающим новым понятиям, чаще всего неправильно переведенным с иностранного языка, чем по серьезным отечественным научно-технологическим и социально-экономическим обоснованиям.

Не исключение здесь понятия новшество, новация, инновация. Чтобы быть правильно понятым, нужно дистанцироваться от неверно переведенных с английского языка соответствующих слов. Дадим определения.

Новация - это процесс освоения или внедрения (проникания в сопротивляющуюся экономическую среду) новшества. А инновация - непрерывный во времени процесс круговорота новшеств, то есть некий жгут циклических процессов новаций [10].

Колебательная адаптация. Из термодинамики известно, что в косном веществе энтропия, то есть градиент энергетических потерь, со временем возрастает, а в биологических объектах, наоборот, снижается. Иначе говоря, живое вещество организует круговорот косного вещества и самого себя так, что удельные потери вещества, энергии и информации (энергетического импульса) уменьшались или были постоянными. Это и есть вектор эволюции жизни как космического явления по В.И. Вернадскому. Оказывается, что только колебательная адаптация к изменяющимся условиям обитания или произрастания позволяет выживать и 
развиваться дальше популяциям животных (включая и человека до появления сельского хозяйства 9-12 тысяч лет назад) и растений. Культурные растения и животные на это не способны и без человека они быстро дичают.

В любом виде живого вещества оба закона роста и гибели присутствуют совместно и такую совместность мы назвали биотехническим законом. Он проявляется в любых системах, в том числе и из косного вещества, преобразованного живым веществом.

В итоге любой человек или сообщество людей е техническими устройствами являются носителями биотехнического закона. Как будет показано в других статьях, не исключение здесь и научно-технологическое развитие России.

Экспертиза. Напомним из толкового словаря русского языка, что экспертиза - это рассмотрение, исследование каких-либо вопросов, решение которых требует специальных знаний в области науки, техники, искусства и т.п.

Таким образом, термин «экспертиза» сам по себе подразумевается проведение каких-то научно-технических исследований. Поэтому эксперт (от лат. expertus - опытный) - специалист, выполняющий экспертизу, по определению должен быть опытным в научнотехнических исследованиях человеком. Но опытным не станешь без конкретных результатов по теориям, методам и методикам, изобретениям.

Практический опыт жизнедеятельности для экспертизы качества территории также имеет немаловажное значение. Но в нашей стране экспертиза только начинает возникать: в советское время любую экспертизу делали сами чиновники. Однако, например, за рубежом экологическую экспертизу выполняет население.

В современной России создано экспертное сообщество РИНКЦЭ.

Одним из основополагающих принципов, которым руководствуется в своей работе ФГБНУ НИИ РИНКЦЭ, ЯВЛЯется повсеместное использование информационных технологий при решении задач в рамках основных направлений деятельности института.

Такой подход позволяет объединять информационные ресурсы, регламентировать информационные потоки, проводить научно-исследовательские и экспертные работы на основе аналитической обработки больших информационных массивов. Практически все основные задачи, обеспечивающие функции Минобрнауки России, решаются институтом на базе единых информационных технологий.

Носителями инновационных процессов $[4,6,12]$ всегда является молодёжь, поэтому обучение студентов экспертизе вполне возможно проводить через выполнение конкретных НИРС [11]. Однако, для рывка в научно-техническом творчестве молодёжи нужно вначале создать правовые условия [6] для раскрепощения личности изобретателя [9]. По нашему мнению, правовые условия для научно-технического и иного творчества можно создать 
только на основе всеобщей декларации прав человека [8-11]. Диверсификация экономики России требует одновременного рассмотрения вейвлет-сигналов из прошлого по структурной динамике внутри страны при развивающейся конкурентной внешней среде. Для этого требуется вначале провести факторный анализ.

Факторный анализ понимается как выявление устойчивых закономерностей изменений значений каждого из множества учитываемых параметров изучаемой эргатической системы, а также математических связей между всеми факторами.

Кроме того, факторный анализ в частных случаях включает многие методы экономического анализа, в которых изучаются без применения математики различные соотношения между факторами (метод анализа иерархий Саати). Вначале должна быть разработана эвристическая схема квантификации фактов. Причем такая схема всегда субъективна и во многом исходит из опыта эксперта в научно-технических или иных исследованиях.

В методологии идентификации устойчивых законов по статистическим данным [1-13] главным требованием становится проверка истинности знаний на количественном уровне, то есть добротность, полнота и погрешность измерений. Истинность устойчивых законов принимается как аксиома и отпадает проверка адекватности выявленных закономерностей.

Таким образом, значительно расширяется этап первичной обработки эмпирического материала, в особенности в виде количественно измеренных исходных данных. И это обстоятельство превращает процесс идентификации в индуктивный подход (по Рене Декарту).

Большая доля содержательной (эвристической) информации появляется в процессе идентификации биотехнических закономерностей. Индуктивный подход во многих случаях позволяет даже исключить этапы анализа проблемной ситуации и перейти к этапу осмысления и выражению результатов познания новыми научно-техническими решениями.

Общая биотехническая закономерность. Индуктивно, на основе десятков тысяч примеров идентификации статистических выборок из различных областей науки и техники, были выявлены всего две обобщенные математические модели, которые записываются так:

а) обобщенная детерминированная (трендовая) модель для дедуктивной идентификации по значениям факторов и связей между ними;

б) общая волновая функция в виде асимметричного вейвлет-сигнала.

Как правило, только человек вводит в природные процессы негативные колебательные возмущения. Природные катастрофы влияют вейвлет-сигналами переменных частот.

Все детерминированные тенденции моделировали идентификацией с использованием двухчленной биотехнической закономерности

$$
y=a_{1} x^{a_{2}} \exp \left(-a_{3} x^{a_{4}}\right)+a_{5} x^{a_{6}} \exp \left(-a_{7} x^{a_{8}}\right)
$$

В таблице 1 приведена форма для компактной записи параметров общей модели (1). 
Параметры закономерностей сверхсильных бинарных связей факторов (форма)

\begin{tabular}{|c|c|c|c|c|c|c|c|c|c|c|}
\hline \multirow{3}{*}{$\begin{array}{c}\text { № } \\
\Pi / \Pi\end{array}$} & \multirow{3}{*}{$x \rightarrow y$} & \multicolumn{8}{|c|}{$y=a_{1} x^{a_{2}} \exp \left(-a_{3} x^{a_{4}}\right)+a_{5} x^{a_{6}} \exp \left(-a_{7} x^{a_{8}}\right)$} & \multirow{3}{*}{$\begin{array}{c}\text { Коэф. } \\
\text { корреля- } \\
\text { ции }\end{array}$} \\
\hline & & \multicolumn{4}{|c|}{ Первая составляющая } & \multicolumn{4}{|c|}{ Вторая составляющая } & \\
\hline & & $a_{1}$ & $a_{2}$ & $a_{3}$ & $a_{4}$ & $a_{5}$ & $a_{6}$ & $a_{7}$ & $a_{8}$ & \\
\hline 1 & & & & & & & & & & \\
\hline 2 & & & & & & & & & & \\
\hline$\ldots$ & & & & & & & & & & \\
\hline
\end{tabular}

Для расчетов в программной среде Excel применяется конструкция формулы (1) с числовыми значениями её параметров, полученными после идентификации по статистическим выборкам динамических рядов или же табличных моделей в виде «срезов» во времени.

Устойчивая волновая закономерность (табл. 2) для факторных связей в виде асимметричных вейвлет-сигналов имеет вид уравнения

$$
y=\sum_{i=1}^{m} y_{i}, y_{i}=a_{1 i} x^{a_{2 i}} \exp \left(-a_{3 i} x^{a_{4 i}}\right) \cos \left(\pi x /\left(a_{5 i}+a_{6 i} x^{a_{7 i}}\right)-a_{8 i}\right) .
$$

Параметры общего уравнения факторной связи (форма)

\begin{tabular}{|c|c|c|c|c|c|c|c|c|}
\hline \multirow{2}{*}{$x \rightarrow y$} & \multicolumn{4}{|c|}{ Амплитуда колебания } & \multicolumn{4}{|c|}{ Полупериод и сдвиг колебания } \\
\hline & $a_{1 i}$ & $a_{2 i}$ & $a_{3 i}$ & $a_{4 i}$ & $a_{5 i}$ & $a_{6 i}$ & $a_{7 i}$ & $a_{8 i}$ \\
\hline & & & & & & & & \\
\hline & & & & & & & & \\
\hline & & & & & & & & \\
\hline & & & & & & & & \\
\hline
\end{tabular}

Корреляционная матрица факторного анализа. В таблице 3 приведена полная корреляционная матрица монарных (на основе рангового или рейтингового распределения) и бинарных (между парами взаимно влияющих факторов) связей между четырьмя факторами.

Таблица 3

Корреляционная матрица полного факторного анализа

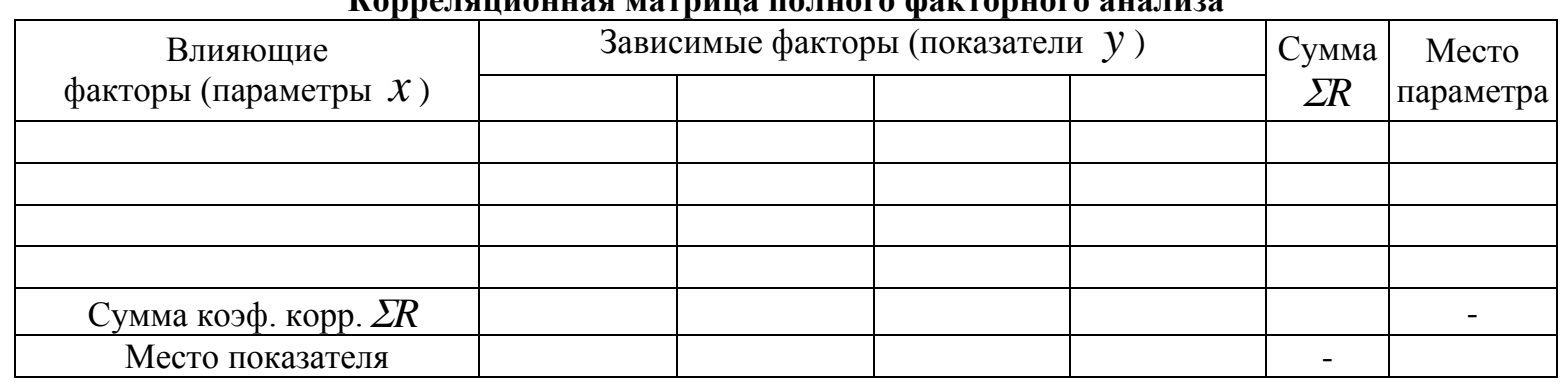

Пример исходных данных. Дождевые воды с кровель зданий предприятия ОАО “ТГК5" и дорог с твердым покрытием, а также стоки от опорожнения и продувки градирен, уборки полов и двора, самотеком по сети канализации направляются в ливнеотстойник [1].

Данные OAO “ТГК-5” за 2005-2008 гг. по месяцам выпуска продукции (тепловой и электрической энергии), а также данные водно-химической лаборатории по концентрациям веществ в ливнеотстойнике, превышающих ПДК, представлены в таблице 4. ПДК нефти в водоеме рыбохозяйственного назначения равен 0,05 , железа $-0,1$, меди $-0,001$, БПК 
Таблица 4

Производимая продукции предприятия и концентрации веществ в ливнеотстойнике [1]

\begin{tabular}{|c|c|c|c|c|c|c|}
\hline \multirow{3}{*}{$\begin{array}{c}\text { Время } \\
\text { (год, месяц) }\end{array}$} & \multicolumn{2}{|c|}{ Продукция } & \multicolumn{4}{|c|}{ Загрязнение } \\
\hline & \multirow{2}{*}{$\begin{array}{c}\text { Тепловая } \\
\text { энергия, Гкал }\end{array}$} & \multirow{2}{*}{$\begin{array}{c}\text { Электрическая } \\
\text { энергия, тыс. кВт-ч }\end{array}$} & \multicolumn{4}{|c|}{ Концентрация веществ в ливнеотстойнике, мг/л } \\
\hline & & & нефть & железо & медь & БПК \\
\hline 2005 г. Январь & 133991 & 113244 & 0,06 & 0,27 & 0,009 & 3,0 \\
\hline Февраль & 134534 & 99009 & 0,06 & 0,32 & 0,009 & 2,8 \\
\hline Март & 135173 & 103043 & 0,07 & 0,23 & 0,015 & 2,9 \\
\hline Апрель & 93901 & 78366 & 0,09 & 0,60 & 0,018 & 4,8 \\
\hline Май & 47295 & 73325 & 0,09 & 0,37 & 0,014 & 3,0 \\
\hline Июнь & 11667 & 46505 & 0,07 & 0,52 & 0,02 & 3,9 \\
\hline Июль & 42371 & 52631 & 0,07 & 0,34 & 0,013 & 5,6 \\
\hline Август & 41671 & 62445 & 0,07 & 0,51 & 0,012 & 4,0 \\
\hline Сентябрь & 49703 & 65847 & 0,08 & 0,33 & 0,01 & 3,2 \\
\hline Октябрь & 81378 & 82025 & 0,09 & 0,24 & 0,009 & 4,4 \\
\hline Ноябрь & 102778 & 105063 & 0,08 & 0,45 & 0,01 & 4,3 \\
\hline Декабрь & 125283 & 117303 & 0,08 & 0,37 & 0,012 & 3,6 \\
\hline 2006 г. Январь & 158356 & 114015 & 0,08 & 0,28 & 0,01 & 4,1 \\
\hline Февраль & 137520 & 95148 & 0,07 & 0,26 & 0,02 & 3,9 \\
\hline Март & 120345 & 105620 & 0,07 & 0,25 & 0,013 & 4,6 \\
\hline Апрель & 92471 & 86713 & 0,08 & 0,5 & 0,025 & 3,5 \\
\hline Май & 39447 & 68946 & 0,07 & 0,34 & 0,01 & 4,1 \\
\hline Июль & 44627 & 48531 & 0,07 & 0,47 & 0,005 & 4,3 \\
\hline Август & 46122 & 41215 & 0,08 & 0,59 & 0,01 & 4,6 \\
\hline Сентябрь & 43963 & 61206 & 0,07 & 0,31 & 0,007 & - \\
\hline Октябрь & 74563 & 87756 & 0,08 & 0,60 & 0,008 & - \\
\hline Ноябрь & 93596 & 104334 & 0,08 & 0,32 & 0,009 & - \\
\hline Декабрь & 97743 & 106093 & 0,08 & 0,55 & 0,02 & - \\
\hline 2007 г. Январь & 102395 & 112639 & 0,08 & 0,53 & 0,02 & - \\
\hline Февраль & 126615 & 100381 & 0,08 & 0,50 & - & 2 \\
\hline Март & 95945 & 102687 & 0,07 & 0,39 & 0,02 & - \\
\hline Апрель & 76955 & 83495 & 0,08 & 0,43 & 0,012 & - \\
\hline Май & 49180 & 70931 & 0,06 & 0,57 & 0,005 & - \\
\hline Июнь & 14782 & 16336 & 0,04 & 0,50 & 0,003 & 4,2 \\
\hline Июль & 44200 & 42233 & 0,05 & 0,44 & 0,005 & 4,6 \\
\hline Август & 43779 & 52894 & 0,05 & 0,48 & 0,01 & - \\
\hline Сентябрь & 54411 & 66081 & 0,06 & 0,48 & 0,012 & 5 \\
\hline Октябрь & 72742 & 82120 & 0,04 & 0,38 & 0,01 & 5,2 \\
\hline Ноябрь & 101296 & 102338 & 0,05 & 0,48 & 0,018 & 1,7 \\
\hline Декабрь & 119876 & 106582 & 0,05 & 0,22 & 0,018 & 1 \\
\hline 2008 г. Январь & 126689 & 114621 & 0,06 & 0,22 & 0,015 & 3,1 \\
\hline Февраль & 102374 & 104561 & 0,05 & 0,27 & 0,014 & - \\
\hline Март & 90509 & 103398 & 0,06 & 0,27 & 0,01 & 3,6 \\
\hline Апрель & 71166 & 83099 & 0,06 & 0,4 & 0,013 & 4,1 \\
\hline Июнь & 14005 & 14903 & 0,06 & 0,56 & 0,008 & 3,9 \\
\hline Июль & 46008 & 43004 & 0,06 & 0,4 & 0,004 & - \\
\hline Август & 47084 & 53167 & 0,05 & 0,37 & 0,013 & - \\
\hline Сентябрь & 58667 & 61232 & 0,07 & 0,36 & 0,019 & - \\
\hline Октябрь & 73227 & 92157 & 0,06 & 0,4 & 0,014 & 5,1 \\
\hline Ноябрь & 81419 & 103998 & 0,05 & 0,55 & 0,017 & - \\
\hline Декабрь & 104997 & 97632 & 0,05 & 0,56 & 0,01 & 5,4 \\
\hline
\end{tabular}

За период с 2005-2008 гг. наблюдается превышение концентрации нефти до 1,8 ПДК, железа - до 6 ПДК, содержания меди - до 25 ПДК и БПК

Построение корреляционной матрицы. Из шести факторов таблицы 4 можно получить квадратную матрицу для анализа иерархий с 36 уравнениями $(6 \times 6=36)$, адекватность их показана коэффициента корреляции (табл. 5). 
Общая корреляционная матрица бинарных факторных связей

\begin{tabular}{|l|c|c|c|c|c|c|}
\hline \multirow{2}{*}{$\begin{array}{c}\text { Влияющие } \\
\text { факторы } \boldsymbol{x}\end{array}$} & \multicolumn{5}{c|}{ Зависимые факторы $y$} \\
\cline { 2 - 7 } & $\begin{array}{c}\text { Тепловая } \\
\text { энергия, Гкал }\end{array}$ & $\begin{array}{c}\text { Электроэнергия, } \\
10^{6} \text { кВт-ч }\end{array}$ & Нефть, мг/л & Железо, мг/л & Медь, мг/л & БПК, мг/л \\
\hline Тепловая энергия, Гкал & 1 & $\mathbf{0 , 9 0 3 5}$ & 0,162 & 0,431 & 0,339 & 0,381 \\
\hline Электроэнергия, $10^{6}$.кВт-ч & $\mathbf{0 , 8 9 5 0}$ & 1 & 0,189 & 0,366 & 0,424 & 0,369 \\
\hline Нефть, мг/л & 0,162 & 0,381 & 1 & 0,045 & 0,223 & 0,205 \\
\hline Железо, мг/л & 0,431 & 0,366 & 0,045 & 1 & 0,00046 & 0,299 \\
\hline Медь, мг/л & 0,339 & 0,424 & 0,223 & 0,00046 & 1 & 0,310 \\
\hline БПК, мг/л & 0,381 & 0,369 & 0,005 & 0,299 & 0,310 & 1 \\
\hline
\end{tabular}

В таблице 5 можно выделить две сильнейшие факторные связи (выделены жирно): взаимное влияние тепловой и электрической энергии предприятием ОАО “ТГК-5”.

Выводы. Монарные факторные соотношения, когда переменная влияет на самого себя, в статье не показаны, поэтому в клетках диагонали таблицы 5 коэффициент корреляции равен единице. Это означает, что массив исходных данных по таблице 4 считается достоверным и поэтому проверка ранговых распределений значений факторов на погрешность не проведена.

Анализ моделей показал, что высокой предсказательной научно-технологической силой обладают именно слабые и средние факторные связи, то есть те бинарные соотношения, которые имеют коэффициент корреляции в пределах $0,3 \leq r<0,5$ и $0,5 \leq r<0,7$. Результаты анализа слабых и средних факторных связей, как правило, предопределяют направления дальнейших экспериментов и научных поисков, зачастую приводят к научно-техническим решениям мировой новизны на уровне изобретений.

\section{Список литературы}

1. Дудина Т.С. Оценка влияния ливнеотстойника предприятия ОАО “ТГК-5” г. Йошкар-Ола на качество воды в р. Нолька // Основы рационального природопользования: матер. II междунар. научно-практ. конф. Саратов: Издательский центр “Наука”, 2009. С.122-132.

2. Мазуркин П.М. Активизация изобретательской деятельности студентов // Международный журнал прикладных и фундаментальных исследований. № 12. 2010. С.92-100.

3. Мазуркин П.М. Закономерности устойчивого развития. Йошкар-Ола: МарГТУ, 2002. 302 с. 4. Мазуркин П.М. Инновационные процессы // Наука и технологии. Том. 2. Краткие сообщения XXX Российской школы, посвященной 65-летию Победы. Екатеринбург: УрО РАН, 2010. С.118-120.

5. Мазуркин П.М. Историографический анализ динамики населения России // Международный журнал прикладных и фундаментальных исследований. 2009. № 5. С.56-69.

6. Мазуркин П.М. Материализация научно-технических идей // Наука и технологии. Том. 2. Краткие сообщ. XXX Российской школы, посвящ. 65-летию Победы. Екатеринбург: УрО PAH, 2010. C.124-126.

7. Мазуркин П.М. Популяционная социометрика образовательных организаций // Успехи современного естествознания. 2012. № 2. С.97-102.

8. Мазуркин П.М. Правовое состояние России в инновационной деятельности // Международный журнал прикладных и фундаментальных исследований. № 8. 2010. С.41-57.

9. Мазуркин П.М. Раскрепостить творческую личность изобретателя // Международный журнал экспериментального образования. № 9. 2010. С.52-67.

10. Мазуркин П.М. Самоорганизация студента в инновационном обучении и изобретательской деятельности: науч.-учеб. изд. Йошкар-Ола: МарГТУ, 2011. 255 с. 
11. Мазуркин П.М. Социокультурная динамика и популяционная эконометрика // Успехи современного естествознания. 2012. № 2. С.89-96.

12. Мазуркин П.М. Формирование материальной ткани технической деятельности // Инновац. проектир. в образов., технике и технологии: межвузовский сборник научных трудов. Волгоград: ВолГТУ, 1996. С.105-109.

13. Мазуркин П.М. Эконометрика России: кризис конца XX века // Теория предвидения и будущее России: материалы V Кондратьевских чтений. М.: Институт экономики РАН, 1997. C.214 - 222.

The list of references

1. Dudina T.S. Assessing the impact of livneotstoynika enterprise JSC "TGC -5" Yoshkar-Ola on the water quality in the river Nolka // Basics of Environmental Management: Proceedings of the II International Scientific Conference Saratov Publishing Center "Science", 2009. P.122 -132.

2. Mazurkin P.M. Activation of inventive activity of students // International journal of applied and basic research. Number 12. 2010. P.92 -100.

3. Mazurkin P.M. Patterns of sustainable development. Yoshkar-Ola Mari State Technical University, 2002. $302 \mathrm{p}$.

4. Mazurkin P.M. Innovative Processes // Science and Technology. Tom. 2. Brief communications XXX Russian schools to mark the 65th anniversary of the Victory. Ekaterinburg: Ural Branch of Russian Academy of Sciences, 2010. P.118 - 120.

5. Mazurkin P.M. Historiographical analysis of the dynamics of the population of Russia // International journal of applied and basic research. 2009. Number 5. P.56 -69.

6. Mazurkin P.M. The materialization of scientific and technical ideas // Science and Technology. Tom. 2. Brief message. XXX Russian school dedicated. 65th anniversary of the Victory. Ekaterinburg: Ural Branch of Russian Academy of Sciences, 2010. P.124 -126.

7. Mazurkin P.M. Population sotsiometrika educational organizations // Successes of modern science., 2012. Number 2. P.97 -102.

8. Mazurkin P.M. The legal status of Russian in the innovation // International journal of applied and basic research. Number 8. 2010. P.41 -57.

9. Mazurkin P.M. Unleash the creative personality of the inventor // International Journal of Experimental Education . Number 9. 2010. P.52 -67.

10. Mazurkin P.M. Self-organization of student learning in an innovative and inventive activities : research and educational publishing Yoshkar-Ola Mari State Technical University, 2011. 255.

11. Mazurkin P.M. The socio-cultural dynamics and population Econometrics // Successes of modern science., 2012. Number 2. P.89 - 96.

12. Mazurkin P.M. Forming fabric material and technical activities // Innovative Design in education, engineering and technology: Interuniversity collection of scientific papers. Volgograd VolGTU, 1996. P.105 -109.

13. Mazurkin P.M. Econometrics Russia: the crisis of the late twentieth century // Theory of foresight and the future of Russia: the V Kondratieff readings. Moscow: Institute of Economics, Russian Academy of Sciences, 1997. P.214 - 222.

Рецензенты: ФИО, ученая степень, звание, должность, место работы, город.

Салихов Мухаммет Габдулхаевич, доктор технических наук, профессор, академик РАЕ, почетный работник ВПО РФ, заслуженный деятель науки РМЭ, заведующий кафедрой автомобильных дорог ФГБОУ ВПО «Поволжский государственный технологический университет», 424000. г. Йошкар-Ола, пл. Ленина, 3. Тел. (8362)68-60-72.

Колупаев Борис Иванович, доктор биологических наук, профессор, профессор кафедры водных ресурсов ФГБОУ ВПО «Поволжский государственный технологический университет», 424000. г. Йошкар-Ола, пл. Ленина, 3. Тел. (8362)68-68-58. 